\title{
Hybrid titanium-CFRP laminates for high-performance bolted joints
}

\author{
P.P. Camanho ${ }^{a, *}$, A. Fink ${ }^{\mathrm{b}}$, A. Obst ${ }^{\mathrm{c}}$, S. Pimenta ${ }^{\mathrm{d}}$ \\ ${ }^{a}$ DEMEGI, Faculdade de Engenharia, Universidade do Porto, Rua Dr. Roberto Frias, 4200-465, \\ Porto, Portugal \\ ${ }^{\mathrm{b}}$ DLR German Aerospace Center - Inst. of Composite Structures and Adaptive Systems, \\ Lilienthalplatz 7, D-38108 Braunschweig, Germany \\ ${ }^{\mathrm{c}}$ ESA-ESTEC, Mechanical Engineering Dept. Keplerlaan 1, NL-2200 AG Noordwijk, The \\ Netherlands \\ dINEGI - Instituto de Engenharia Mecânica e Gestão Industrial, Rua Dr. Roberto Frias, 4200-465, \\ Porto, Portugal
}

\begin{abstract}
This paper presents an experimental and numerical investigation of the mechanical response of bolted joints manufactured using new hybrid composite laminates based on the substitution of CFRP plies with titanium plies. This concept is proposed for bolted joints, which are often the critical part of composite structures. Two modeling strategies based on non-linear finite element methods are proposed for the analysis of the bolt-bearing and transition regions of the hybrid laminates. The numerical and experimental results indicate that the use of hybrid composites can drastically increase the strength of CFRP bolted joints and therefore increase the efficiency of this type of connection.
\end{abstract}

Key words: B. Strength, C. Finite element analysis, D. Mechanical testing, E. Joints/joining.

\section{Introduction}

2 One of the main methods used for joining composite components for aircraft and spacecraft 3 applications is mechanical fastening [1]-[2]. Mechanically fastened joints have the advantages 4 of reliability, detachability and inspectability, and represent a well-established and well-known 5 method. However, to reach a satisfactory structural coupling efficiency with composite materials 6 is much more challenging than it is for metals due to the low bearing and shear strengths, the 7 higher notch sensitivity, the dependence of the joint strength on the laminate configuration, and 8 the influence of environmental effects on the mechanical behavior of the joint. These properties 9 represent a limiting factor on the structural performance of composite structures.

* Corresponding author

Email address: pcamanho@fe.up.pt (P.P. Camanho).

Article submitted to Composites - A

14 October 2008 
The load capacity of composite bolted joints is typically increased by means of a local laminate build-up at the structure coupling area. The resulting laminate thickness increase leads to additional laminate stresses due to eccentricities, particularly in the case of single-shear joints, to complex geometries of the adjacent structures, as well as to a significant weight increase due to larger grip lengths, larger bolt diameters and heavier metallic fittings. The increasing requirements for weight reduction and cost efficiency for aerospace and spacecraft structures demand the development of alternative advanced coupling techniques.

One of such alternatives is the use of bonded metallic inserts [3]-[6]. However, this technique has proved to be effective only if specially designed inserts, that promote alternative paths for the load transfer, are used in single-shear lap joints [7]-[8].

The coupling efficiency of highly loaded composite joints has been proven by the research activities conducted at the German Aerospace Centre [9]-[11], to be considerably improved by the use of a local reinforcement of the joining area with thin high-strength metal foils using ply substitution techniques. The use of a hybrid composite increases the bearing strength, the coupling stiffness and reduces the sensitivity of the mechanical properties to the laminate configuration and environmental effects. Higher absolute mechanical properties prevent any local laminate thickening and eccentricities and allow possible reductions of the number of bolts and bolt rows, resulting in a mechanically and cost efficient design.

The local reinforcement technique applied to the bolt-bearing region is accomplished by the gradual substitution of specific composite plies by titanium foils within the coupling region, see Figure 1. The remaining composite plies are not interrupted and pass from the pure composite region through the transition region to the hybrid region, thus acting there as adhesion interlayers between each embedded metal foil. The continuous plies should preferably contribute most to the total load carrying of the laminate.

[Fig. 1 about here.]

Previous experimental analysis [9] have demonstrated that the use of hybrid laminates with $20 \%$ titanium content increases the tensile strength of a three-row bolted joint by $91 \%$ when compared to that of a full carbon-fibre reinforced plastic (CFRP) laminate, whereas the specific tensile strength is increased by $32 \%$. This means that the joint based on the hybrid composite is lighter and it does not require a local increase of the thickness that would trigger secondary bending effects in single-shear joints and increase bolt bending. Therefore, the weight gains in actual composite structures may be even higher than the values obtained by comparing the specific joint strength of test coupons.

Based on the promising preliminary experimental results obtained in [9]-[11], it is necessary to define a methodology to design hybrid composites. Therefore, the objectives of this paper are to present the numerical analysis of the inelastic response of hybrid carbon-epoxy/titanium bolted joints, which can support the design of these joints, and to further assess the gains that can be obtained by locally reinforced composites using both the results of the numerical models and the experimental data obtained in representative test specimens.

The mechanical performance improvement in comparison to the reference conventional design is presented. Taking into account that the new technology proposed can only be effective if the strength of the transition region is higher than that of the bearing (hybrid) region (Figure 1 ), the experimental tests and numerical analysis are conducted in specimens representative of 
these two regions. The delamination behavior of the transition region is analyzed by means of numerical simulations based on plane-stress models. The simulation of the bolt bearing region is performed using a three-dimensional model that accounts for ply failure mechanisms, combined with a plasticity model that simulates the mechanical response of the titanium inserts. The numerical models are validated by comparing the predictions with experimental data obtained in test specimens representative of the bolt-bearing and transition regions.

\section{Manufacturing, material characterization and specimen configurations}

\subsection{Manufacturing}

The selection of the metal to be used in the locally reinforced region of the laminate is of primary importance to the efficiency of the technology proposed. Taking into account that titanium has good specific mechanical properties, is electrochemically compatible with carbon, and has a relatively low coefficient of thermal expansion, this material is selected for the metal layers. The standard titanium alloy Ti-6-4 (Ti 6Al-4V) was excluded because it has a poor cold workability and a low strength (about $980 \mathrm{MPa}$ ). Therefore, a meta stable beta-alloy Ti-15V3Cr-3Sn-3Al with reference Ti 15-3-3-3 titanium alloy was selected. This alloy has a good cold workability and hardening which enable a flexible tailoring of sheet thickness with moderate costs. In addition, the strength of Ti $15-3-3-3$ with a nominal thickness of $0.25 \mathrm{~mm}$ is $1634 \mathrm{MPa}$.

The composite material selected for the study was the carbon-fibre reinforced epoxy M40$\mathrm{J} / \mathrm{CYCOM}$ 977-2. This material is supplied as unidirectional pre-impregnated plies. After curing, the nominal ply thickness is $0.25 \mathrm{~mm}$.

The hybrid composite material can be manufactured using different technologies such as prepreg lay-up, resin infusion and fibre placement. All these techniques were successfully demonstrated in previous investigations [9]-[11]. The pre-preg technique was used in the test specimens manufactured here, where the lay-up process consists of stacking alternate layers of titanium alloy foils (Ti 15-3-3-3) and pre-preg plies without adding any adhesive. The selected titanium surface pre-treatment consists of a surface cleaning and a chemical pickling pre-treatment which provides an optimal adhesion quality between the metal and the pre-preg resin. Higher adhesion performance and delamination growth attenuation is achieved generating a metal surface macro-roughness by means of surface grit blasting.

\subsection{Material characterization}

The standard material properties of the M40-J/CYCOM 977-2 CFRP are shown in Tables 1 and 2. The shear modulus $\mathrm{G}_{23}$ was calculated assuming transverse isotropy and a Poisson ratio $v_{23}=0.5$.

[Table 1 about here.]

[Table 2 about here.] 
The coefficients of thermal expansion of M40-J/CYCOM $977-2$ are $\alpha_{11}=-0.84 \times 10^{-6} /{ }^{\circ} \mathrm{C}$ and $\alpha_{22}=29.1 \times 10^{-6} /{ }^{\circ} \mathrm{C}$.

Besides the "standard" material properties presented in Tables 1 and 2, the analysis models require the values of the fracture toughness. The values of the mode I and mode II interlaminar fracture toughness were measured for the carbon-carbon and for the carbon-titanium interfaces, and are reported in Table 3. The mode I interlaminar fracture toughness is measured using the double-cantilever beam test specimen [12], and the mode II interlaminar fracture toughness is measured using the transverse crack tension test [13].

[Table 3 about here.]

The values reported in Table 3 enable the calculation of the in-situ shear $\left(S_{L}^{\text {is }}\right)$ and transverse tensile $\left(\mathrm{Y}_{T}^{\mathrm{is}}\right)$ strengths used in the analysis models according to the models presented in [14]. The calculated in-situ strengths are presented in Table 4.

[Table 4 about here.]

The fracture toughness for longitudinal fracture under tension and compression were not measured for M40-J/CYCOM 977-2. Instead, the values previously measured for IM7-8552, $G_{1+}=81.5 \mathrm{~N} / \mathrm{mm}$ (fibre tension), $G_{1-}=106.3 \mathrm{~N} / \mathrm{mm}$ (fibre compression) are used in the numerical models [25].

The mechanical properties of the titanium sheet are presented in Table 5 . The coefficient of thermal expansion of Ti $15-3-3-3$ is $\alpha_{\mathrm{T}}=9.2 \times 10^{-6} /{ }^{\circ} \mathrm{C}$.

[Table 5 about here.]

\subsection{Specimen configurations}

In the design of hybrid composites it is necessary to ensure that the strength of the transition region show in Figure 1 is higher than that of the bolt-bearing region. Therefore, the experimental programme was conducted in two different types of test specimens, one representing the bearing region and the other representing the transition region. The lay-up of the specimens manufactured is shown in Table 6. The test specimens with references B7/TT2 and B7/TT3 have the same lay-up, but different lengths of the titanium plies.

[Table 6 about here.]

The details of the specimens manufactured for the bearing tests are shown in Table 7 ; the bearing test specimens are $170 \mathrm{~mm}$ long, $45 \mathrm{~mm}$ wide, $3 \mathrm{~mm}$ thick, and have a hole with a nominal diameter of $6.35 \mathrm{~mm}$. No end-tabs are used for the bearing test specimens.

[Table 7 about here.]

The configuration and stacking sequence of the test specimens manufactured for the analysis of the transition region are presented in Table 8 . The specimens are $250 \mathrm{~mm}$ long, $15 \mathrm{~mm}$ wide and $3 \mathrm{~mm}$ thick. End-tabs with a length of $70 \mathrm{~mm}$ were bonded to the test specimens. 
Figure 2 schematically shows the configurations of the specimens under investigation.

[Fig. 2 about here.]

\section{Test and analysis of the bearing region}

\subsection{Testing}

The specimens are tested in tension using a Zwick 1484 test machine, under displacement control, and with a test speed of $1 \mathrm{~mm} / \mathrm{min}$. Five specimens are tested for each configuration. A H8f7 tolerance between the hole and the bolt is used, resulting in a small clearance between the two components. Finger-tight clamping conditions are used in all the tests performed.

Figure 3 shows the measured relation between the bearing stress, defined as $\sigma^{b}=\frac{P}{d t}$ where $P$ is the load, and the cross-head displacement measured for each test specimen.

[Fig. 3 about here.]

Figure 4 shows the through-the-thickness micrography of the bearing plane of the B1 and of the B7/TT2 test specimens loaded to $40 \%, 60 \%, 80 \%$ and $100 \%$ of the failure stress.

[Fig. 4 about here.]

It is observed that the titanium plies develop cracks and the $0^{\circ}$ plies present fibre kink bands at $80 \%$ of the failure stress. A major through-the-thickness shear crack, that starts at the bottom ply and propagates towards the end of the washer, is visible at the failure stress.

\subsection{Numerical models}

Abaqus [15] finite element code is used for all the numerical analysis presented here. The specimen is meshed using 8-node continuum shell SC8R elements, using two different levels of refinement (see Figure 5). In the neighborhood of the hole, where damage takes place, a refined mesh is used, using the smaller elements, with the approximate dimensions $0.25 \mathrm{~mm} \times$ $0.25 \mathrm{~mm} \times 0.25 \mathrm{~mm}$, along the edge of the hole. The coarse mesh, approximately four times less refined, is connected to the fine mesh by a surface-to-surface based TIE constraint, which allows the correct simulation of the stress distribution at the mesh-transition region. In both the refined and coarse regions, one element per ply is used along the thickness direction. The bolt is modeled by a titanium cylinder, meshed with fully-integrated C3D8 three-dimensional (3D) linear hexahedral elements. The mesh of the bolt is twice less refined than that of the composite.

[Fig. 5 about here.] 
The mid-plane symmetry of the laminate (plane 1-2 in Figure 5) is taken into account in the analysis of all specimens, by applying appropriate boundary conditions. Whenever possible (absence of $\pm 45^{\circ}$ plies), symmetry boundary conditions with respect to the plane 1-3 shown in Figure 5 are also used to reduce computation time.

The progressive damage model implemented in Abaqus [15] was used to simulate the failure mechanisms that occur in the composite plies in the refined region of the model. To prevent the problems that occur when using damage models with large elements [16]-[17], a linearelastic response is imposed in the coarse mesh. The progressive damage model uses the Hashin failure criteria [18] for the prediction of the onset of the different types of intralaminar damage that occur in laminated composites: fibre tensile fracture, fibre kinking, matrix tensile cracking and matrix compressive failure. In addition, the damage model predicts the accumulation and propagation of the different ply damage mechanisms. This is accomplished by defining a linear damage evolution law that uses the material toughness for each failure mechanism to ensure a mesh-independent result [15],[19]. The full details of the damage model can be found in [19]. An elastic-plastic material model is used for the titanium plies used in the hybrid composite and in the bolt. The Von Mises criterion is used to predict the onset of plastic flow, and the plastic deformation is simulated using an isotropic hardening behavior and an associated flow rule.

An initial thermal step, from $180^{\circ} \mathrm{C}$ to $25^{\circ} \mathrm{C}$, is applied to simulate the curing process. During the thermal step the laminate was allowed to contract freely, and the bolt (without thermal load applied) was centered in the hole by specifying kinematic constraints. An intermediate step, corresponding to the attachment of the specimen to the test machine, is applied afterwards. Finally, the bearing test is simulated: a constant velocity along the 1-axis shown in Figure 5 is imposed to the nodes at the axis and top surface of the bolt using proper kinematic conditions are imposed to ensure the correct alignment of the parts. The previous kinematic constraint between the bolt and the specimen's hole is removed, and a contact definition is activated to allow the surface of the bolt to drag the laminate during the simulation of the test. Friction between the bolt and the laminate is taken into account in the analysis. The contact is assumed to follow Coulomb's friction law and a coefficient of friction between the bolt and the laminate of 0.3 is used [20].

The non-catastrophic bearing failure mode, characterized by a progressive elongation of the hole, is predicted for all specimens simulated. Figure 6 shows the predicted region where fibre kinking takes place in the $0^{\circ}$ ply at $40 \%, 60 \%$ and $80 \%$ of the maximum predicted bearing stress of the B7/TT2 specimen. Figure 7 shows the value of the equivalent plastic strain, defined as $\bar{\varepsilon}=\int_{0}^{t} \sqrt{\frac{2}{3} \dot{\varepsilon}^{p l}: \dot{\varepsilon}^{p l}} d t$, where $\dot{\varepsilon}^{p l}$ is the time derivative of the plastic strain tensor, on the top titanium layer for the same applied loads to the B7/TT2 specimen.

[Fig. 6 about here.]

[Fig. 7 about here.] 


\subsection{Discussion}

Figure 8 compare the numerical and experimental relations between the bearing stress and the bolt displacement.

[Fig. 8 about here.]

Table 9 presents the predicted bearing strengths, $\bar{\sigma}^{b}$, for the different specimens simulated and the corresponding experimental results. Table 10 compares the predicted and experimentally measured bearing stress at the onset of non-linear response of the joint, $\sigma_{e}^{b}$. This bearing stress defines the elastic limit of the joint.

[Table 9 about here.]

[Table 10 about here.]

The results shown in Table 9 indicate that the numerical models developed can predict with a remarkable accuracy the maximum bearing stress sustained by the different joint configurations (monolithic CFRP and hybrid). The models are also able to predict within reasonable accuracy the elastic limit of the joints. One possible reason for the the higher errors obtained in the prediction of the elastic limit is the fact that the Abaqus damage model [15] is defined for plane stress conditions, i.e., although the SC8R continuum shell elements are volumetric elements, they can only predict the in-plane components of the stress tensor. This means that the out-ofplane components of the stress tensor that are present along the hole of the laminate [21]-[23] are not used in the failure criteria. In addition, Abaqus uses Hashin's [18] failure criterion to predict fibre kinking, defined as $\frac{\sigma_{11}}{X_{c}}-1 \leq 0$, which does not take into account the effect of the shear stresses on the onset of fibre kinking. However, the shear stresses do play an important role in fibre kinking [24] and their absence in the failure criteria results in an over-prediction of the elastic limit.

Figure 8 shows that the experimentally measured displacement at the peak value of the bearing stress is higher than that predicted by the numerical models. The reasons for this difference can be attributed to the fact that the delaminations that were observed in the micrographs of the test specimens were not simulated in the FE models. For example, in the specimen B1 a delamination between the $+45^{\circ}$ and the $0^{\circ}$ plies, triggered by a fibre kink band, was experimentally observed (Figure 4). The simulation of the interaction between fibre kinking and delamination would require a fully 3D damage model using at least five elements per ply thickness [26], that would render the model unfeasible to be solved within a reasonable time. In addition, shear fracture of the titanium plies was observed in the test specimen B7/TT2 (Figure 4). In spite of the fact that the FE models account for the elasto-plastic response of the titanium plies, they do not simulate their fracture. After cracking, the titanium plies can still transfer load under compression due to the contact between the crack planes; however the relative movement of the fractured surfaces of the titanium plies increase the compliance of the joint, leading to a higher displacement at the peak load.

It is observed that the maximum value of the predicted equivalent plastic strain at $80 \%$ of the failure load (Figure 7) is higher than the equivalent plastic strain that is measures in a tensile test of a sheet of titanium. This result is consistent with the cracks observed in the titanium ply (Figure 4). In addition, the fibre kink bands predicted in the top $0^{\circ}$ ply by the numerical 
model shown in Figure 7 are also observed in the experimental observations of Figure 4.

The results presented in Figure 3 and in Table 9 show that the bearing strength increases with the titanium content: when increasing the titanium content from $0 \%$ to $50 \%$ the bearing strength increases $154 \%$. In addition, the specific bearing strength, defined here as the ratio between the bearing strength and the mass of the joint, increases 29\%. Another relevant observation is that the stiffness of the joint, which is a relevant parameter for spacecraft applications, is higher in the hybrid joints.

\section{Test and analysis of the transition region}

\subsection{Testing}

The specimens are tested in tension using a Zwick 1484 test machine, under displacement control, and with a test speed of $2 \mathrm{~mm} / \mathrm{min}$. Five specimens are tested for each configuration.

Figure 9 shows the relation between the remote stress, defined as the ration between the applied load and the cross-section of the test specimen, and the cross-head displacement for the specimens that represent the transition region and for a baseline specimen manufactured using only in CFRP. This relation is linear until the peak stress and the hybrid laminates marginally decrease the strength of a monolithic CFRP specimen.

[Fig. 9 about here.]

Figure 10 shows the C-scan performed in the specimen B8/TT4 at a load approximately equal to the failure load.

[Fig. 10 about here.]

A delamination propagating form the end of the titanium plies is observed just before the specimen fails as a result of the tensile fracture of the 0 plies. No free-edge delamination is observed in both the hybrid and fully composite regions of the test specimen.

\subsection{Numerical models}

The numerical analysis of the test specimens of the transition region is performed by modeling the free edge of the laminate using two-dimensional plane stress finite elements (Abaqus [15] CPS4 4-node elements). The analysis of the transition region of the hybrid laminates using linear elasticity creates a difficulty since the multi-material corners result in singularities in the stress field. This, in turn, means that the maximum stress predicted by the numerical model increases with the mesh refinement. To mitigate these difficulties and to simulate the possible delamination growth from the singular points, cohesive finite elements previously developed and implemented as Abaqus user-defined elements [27] are used along the Titanium-CFRP and CFRP-CFRP interfaces. In addition, cohesive finite elements are also placed in the elements that represent the $90^{\circ}$ plies at the place where the titanium layers terminate (Figure 2). Using 
cohesive elements, the stress field is bounded and a fracture process zone (FPZ) on the interfaces between the plies and a transverse crack at the end of the titanium ply can be simulated. To correctly capture the kinematics of the cracks that may develop along the vertical TitaniumCFRP interfaces, six elements are used per ply thickness in all plies.

All the specimens are modeled making use of the symmetry along the through-thickness direction. An initial thermal step with $\Delta T=-155^{\circ} \mathrm{C}$ is applied to simulate the curing process. After this step, the edges are constrained in the through-thickness direction, one end of the specimen is clamped, and a displacement was applied to the other edge. The models are $110 \mathrm{~mm}$ long, $3 \mathrm{~mm}$ thick and $15 \mathrm{~mm}$ wide.

The average stress method is used to predict the final failure load of the test specimens loaded in tension. The average stress method consists in applying a failure criterion using the stress distribution averaged over a given distance - the characteristic distance, $d_{c}$ - from a stress concentrator. This method was first proposed by Whitney and Nuismer for the strength prediction of notched composites [28]. Since the FPZ simulated by the cohesive elements is generally confined to the vicinity of the multi-material corner and it does not propagate along the full length of the specimen, it creates a non-uniform stress distribution in the adjoining plies. The non-uniform stress distribution in the $0^{\circ}$ ply is the basis for the application of the average stress method.

Final failure of the laminate is predicted by the average stress method when the $0^{\circ}$ ply fails according to the following equation:

$$
\frac{1}{d_{c}} \int_{0}^{d_{c}} \sigma_{11}(y) d y=X_{T}
$$

The characteristic distance must be determined from a baseline configuration. The B6/TT1 test specimen was selected for the determination of the characteristic distance, and the procedure used consists in the following steps:

(1) Apply the measured remote failure stress to the FE model of one test specimen (the specimen B6/TT1 was selected here).

(2) Identify the critical point in the test specimen.

(3) Determine the stress distribution in the $0^{\circ}$ ply in the vicinity of the critical point, along the fracture plane.

(4) Fit the point-wise stress distribution obtained in the FE model by an appropriate polynomial function using the least-squares method. This procedure defines an approximate function for $\sigma_{11}(y)$.

(5) Solve equation (1) for $d_{c}$.

Once $d_{c}$ is known, steps (2)-(4) are repeated for the other configurations of the transition region. The failure stress is then calculated as the remote stress that leads to a stress distribution satisfying (1).

Figures 11 and 12 show the predicted sequence of failure mechanisms that precede the failure of the B6/TT1 specimen, and the corresponding values of the stress in the loading direction at each ply. 
[Fig. 11 about here.]

[Fig. 12 about here.]

These figures indicate that the failure initiates at the vertical interface between the 90 ply and the titanium ply. The predicted critical region of the B6/TT1 specimen is shown in Figure 13.

[Fig. 13 about here.]

It is observed that there is a small, negligible delamination between the titanium and the $0 /-45$ plies, and between the $90^{\circ}$ and $0^{\circ} /-45^{\circ}$ plies, prior to the collapse of the laminate which results from the fibre fracture of the 0 ply. The application of the methodology outlined above yields a value of $d_{c}=0.18 \mathrm{~mm}$. No plastic deformation of the titanium plies is predicted in the FE analysis.

The predicted critical location of the test specimen B7/TT2 is shown in Figure 14. The first failure mechanism predicted is cracking along the vertical CFRP-Titanium interfaces. Whenever a titanium ply has an adjoining $90^{\circ}$ ply, this crack propagates along the $90^{\circ}$ ply until it reaches the $0^{\circ} / 90^{\circ}$ interface (Figure 14). A small delamination occurs before the specimen fails by fibre fracture.

\section{[Fig. 14 about here.]}

The stresses at the centroid of the elements located in the vicinity of the stress concentration in the critical $0^{\circ}$ ply were obtained from the $\mathrm{FE}$ analysis and the previously obtained value of $d_{c}=0.18 \mathrm{~mm}$ was used for the prediction of final failure. A least-squares approximation of the stress distribution $\sigma_{11}(y)$ based on a fourth-order polynomial was used and the predicted remote failure stress is $\bar{\sigma}^{\infty}=1007.4 \mathrm{MPa}$. No plastic deformation was predicted in the titanium layer.

The predicted critical location of the test specimen B7/TT3 is shown in Figure 15. Like in the specimen TT2, the first failure mechanism predicted is cracking along the vertical CFRPTitanium interfaces. This crack propagates along the $90^{\circ}$ ply until reaching the $0^{\circ} / 90^{\circ}$ interface. A small delamination occurs before the specimen fails by fibre fracture.

[Fig. 15 about here.]

Using the procedure previously outlined, the predicted remote failure stress is $\bar{\sigma}^{\infty}=1087.2 \mathrm{MPa}$. No plastic deformation was predicted in the titanium layer.

The predicted critical location of the test specimen B8/TT4 is shown in Figure 16. The first failure mechanism predicted is cracking along the vertical CFRP (both $90^{\circ}$ and $-45^{\circ}$ plies)titanium interfaces. Final failure is triggered by fibre fracture in the bottom $0^{\circ}$ ply.

[Fig. 16 about here.]

The predicted remote failure stress is $\bar{\sigma}^{\infty}=996.5 \mathrm{MPa}$. No plastic deformation was predicted in the titanium layer. 


\subsection{Discussion}

Table 11 presents the comparison between the predicted failure stress and the corresponding experimental values.

[Table 11 about here.]

The results show in Table 11 indicate that the methodology proposed can predict with good accuracy the strength of the transition region. Also, it is observed that changing the step distance from $5 \mathrm{~mm}$ (specimen B7/TT2) to $15 \mathrm{~mm}$ (specimen B7/TT3) decreases the strength of the transition region by $1.8 \%$. The numerical models predict a linear load-displacement relation up to failure; this result is consistent with the experimental observations.

Table 12 presents the measured remote failure stress for the bearing and transition regions of each configuration tested.

[Table 12 about here.]

It is observed that the strength of the transition region is always higher than that of the boltbearing region. Therefore, the hybrid laminates fail as they should: in the bolt-bearing region and not in the transition region.

Comparing Figures 10 and 16, it can be concluded that the numerical model correctly captured the delamination that preceded the tensile fracture of the B8/TT4 test specimen.

\section{Conclusions}

The work presented in this paper leads to the following conclusions:

- The bearing strength of the laminate increases when the titanium content is increased: there is a remarkable improvement of $158 \%$ when comparing the bearing strength of the B1 specimen (baseline configuration without titanium) with the one of the B8 specimen (with highest titanium content)

- The specific bearing strength of an hybrid joint with $50 \%$ titanium content at the bearing region has a specific bearing strength $29 \%$ higher than that of a monolithic CFRP joint.

- The joint stiffness increases with the titanium content: an increase of stiffness of $31 \%$ is predicted when the titanium content is increased from $0 \%$ to $50 \%$.

- The critical region of the hybrid joints is the bolt-bearing region. The material does not fail prematurely at the transition region.

- Increasing the step distance from $5 \mathrm{~mm}$ to $15 \mathrm{~mm}$ decreases the strength of the B7 configuration by $1.8 \%$.

- The modeling strategy used in the bolt-bearing region yields good predictions for the bearing strength of both monolithic and hybrid composites. Improvements on the prediction of the elastic limit and load-displacement response require the simulation of fracture of the titanium plies and a fully $3 \mathrm{D}$ damage model.

- The models developed for the analysis of the transition region are able to capture the failure mechanisms that trigger structural collapse, and to predict with excellent accuracy the failure 


\section{Acknowledgments}

The work presented in this paper was funded by the European Space Agency (ESA) under the project BOJO - Increase of Bolted Joint Performance.

\section{References}

[1] Camanho PP, Matthews FL. Stress analysis and strength prediction in FRP joints: a review. Composites-Part A 1997;(28):529-547.

[2] Hart-Smith LJ. Design and analysis of bolted and riveted joints. in: L. Tong and C. Soutis, eds. Recent Advances in Structural Joints and Repairs for Composite Materials. Kluwer Academic Publishers, 2003.

[3] Herrera-Franco P, Cloud GL. Strain-relief inserts for composite fasteners- an experimental study. Journal of Composite Materials 1994;(26): 751-768.

[4] Nilsson S. Increasing the strength of graphite/epoxy bolted joints by introducing an adhesively bonded metallic insert. Journal of Composite Materials 1989;(23): 643-650.

[5] Mirabella S, Galea SL. An experimental study into the use of inserts to enhance the static performance of thin composite bolted lap joints.In: 11th International Conference on Composite Materials. Gold Coast, Australia, 1997: 148-57.

[6] Hoa SV, DiMaria A, Feldman D. Inserts for fastening sheet moulding compounds, Composites Structures 1987;(8): 293-309.

[7] Camanho PP, Matthews FL. Bonded metallic inserts for bolted joints in composite laminates. Journal of Materials: Design and Applications- Proceedings of the Institution of Mechanical Engineers Part L 2000;(214):33-40.

[8] Camanho, PP, Tavares, CML, de Oliveira, R, Marques, AT, Ferreira, AJM, Increasing the efficiency of composite single-shear lap joints using bonded inserts, Composites- Part B $2005 ; 36: 372-38$.

[9] Fink, A, Kolesnikov, B, Hybrid titanium composite material improving composite structure coupling, European Conference on Spacecraft Structures, Materials and Mechanical Testing, Noordwijk, The Netherlands, 2005.

[10] Fink, A, Camanho, PP, Canay, M, Obst, A, Increase of bolted joint performance by means of local laminate hybridization, First CEAS European Air and Space Conference, Berlin, Germany, 2007.

[11] Kolesnikov, B, Herbeck, L, Fink, A, CFRP/titanium hybrid material for improving composite bolted joints, Composite Structures, 2008; 83:368-380.

[12] Standard test methods for mode I interlaminar fracture toughness of unidirectional fiber-reinforced polymer matrix composites, ASTM D 5528-01, American Society for Testing and Materials (ASTM), West Conshohocken, PA, U.S.A. 
[13] Prinz, R, Cao, L. Analysis of strain-energy-release rates for unidirectional graphite/epoxy laminates with separated central plies under fatigue loading. Proceedings of the Seventh International Conference on Composite Materials, China, 1989.

[14] Camanho, PP, Dávila, CG, Pinho, ST, Iannucci, L, Robinson, P. Prediction of in-situ strengths and matrix cracking in composites under transverse tension and in-plane shear, Composites-Part A 2006;37:165-176.

[15] ABAQUS 6.5 User's Manual, ABAQUS Inc., Pawtucket, RI, U.S.A. (2005).

[16] Maimí, P, Camanho, PP, Mayugo, JA, Dávila, CG. A continuum damage model for composite laminates: part I - constitutive model. Mechanics of Materials 2007;39:897-908.

[17] Maimí, P, Camanho, PP, Mayugo, JA, Dávila, CG. A continuum damage model for composite laminates: part II - computational implementation and validation. Mechanics of Materials 2007;39:909-919.

[18] Hashin, Z. Failure Criteria for Unidirectional Fiber Composites. Journal of Applied Mechanics 1980;47:329-334.

[19] Lapczyk, I, Hurtado, JA, Progressive damage modeling in fiber-reinforced materials, Composites - Part A 2007;38:2333-2341.

[20] Xiao, Y, Wang, W-X, Takao, Y, Ishikawa, T. The effective friction coefficient of a laminate composite, and analysis of pin-loaded plates. Journal of Composite Materials 2000;34:69-87.

[21] Camanho, PP, Matthews, FL. A Progressive Damage Model for Mechanically Fastened Joints in Composite Laminates. Journal of Composite Materials 1999; 33:2248-2280.

[22] McCarthy M.A., McCarthy, C.T., Lawlor, V.P., Stanley, W.F., Three-dimensional finite element analysis of single-bolt, single-lap composite boltednext term joints: part Imodel development and validatio., Composite Structures 2005;71:140-158.

[23] Hundley, J. H.; Yang, J.-M., and Hahn, H. T. Bearing strength analysis of hybrid titanium composite laminates. AIAA Journal. 2008; 46(8):2074-2085.

[24] Dávila, CG; Camanho, PP, Rose, CA. Failure criteria for FRP laminates. Journal of Composite Materials 2005;39:323-345.

[25] Camanho, PP, Maimí, P, Dávila, CG. Prediction of size effects in notched laminates using continuum damage mechanics. Composites Science and Technology 2007; 67:2715-2727.

[26] Maimí, P, Camanho, PP, Mayugo, JA. A three-dimensional damage model for transversely isotropic composite laminates. Journal of Composite Materials 2008; in press.

[27] Turon, A, Camanho, PP, Costa, J. Dávila, CG. A damage model for the simulation of delamination in advanced composites under variable-mode loading. Mechanics of Materials. 2006;38:1072-1089.

[28] Whitney, JM, Nuismer, RJ. Stress Fracture Criteria for Laminated Composites Containing Stress Concentrations. Journal of Composite Materials 1974;8:253-265. 


\section{List of Figures}

1 Proposed concept: hybrid composite at the bolted joint location. 15

2 Configurations of the test specimens. 16

$3 \quad$ Relation between the bearing stress and the cross-head displacement. 17

$4 \quad$ Optical micrographies of the B1 and B7/TT2 test specimens. 18

$5 \quad$ FE mesh of the bearing specimens. $\quad 19$

$6 \quad$ Predicted evolution of fibre kinking in top $0^{\circ}$ ply of the B7/TT2 specimen. $\quad 20$

$7 \quad$ Predicted evolution of plastic deformation in the top titanium ply of the B7/TT2 specimen. 21

$8 \quad$ Predicted and experimental bearing stress-bolt displacement relations. 22

9 Relation between the remote stress and the displacement for the transition specimens. 23

10 C-Scan of the specimen B8/TT4. 24

11 Detail of B6/TT1 test specimen at $\sigma^{\infty}=225 \mathrm{MPa}$. 25

12 Detail of B6/TT1 test specimen at $\sigma^{\infty}=651 \mathrm{MPa}$. 26

13 Predicted critical region of the B6/TT1 test specimen. 27

14 Predicted critical region of the B7/TT2 test specimen. 28

15 Predicted critical region of the B7/TT3 test specimen. 29

16 Predicted critical region of the B8/TT4 test specimen. 30 


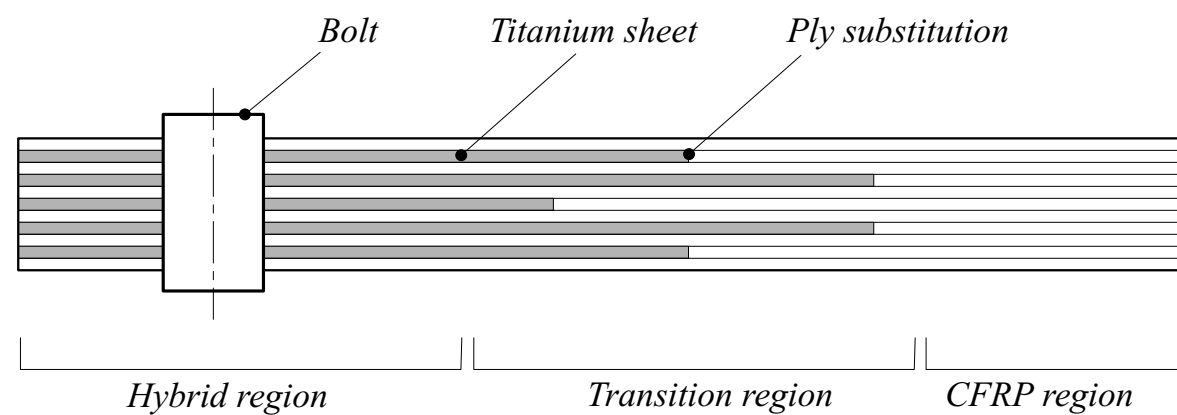

Fig. 1. Proposed concept: hybrid composite at the bolted joint location. 

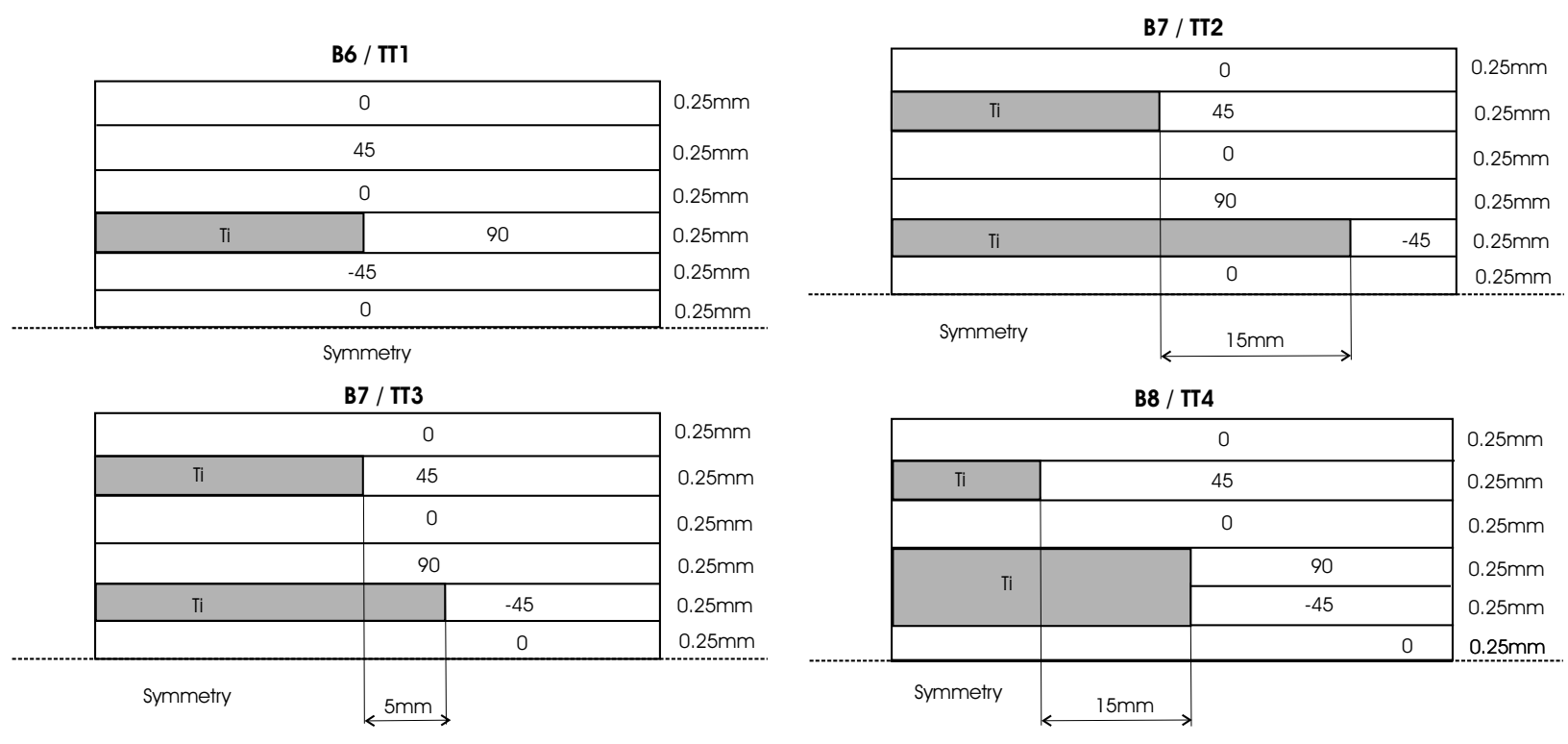

Fig. 2. Configurations of the test specimens. 


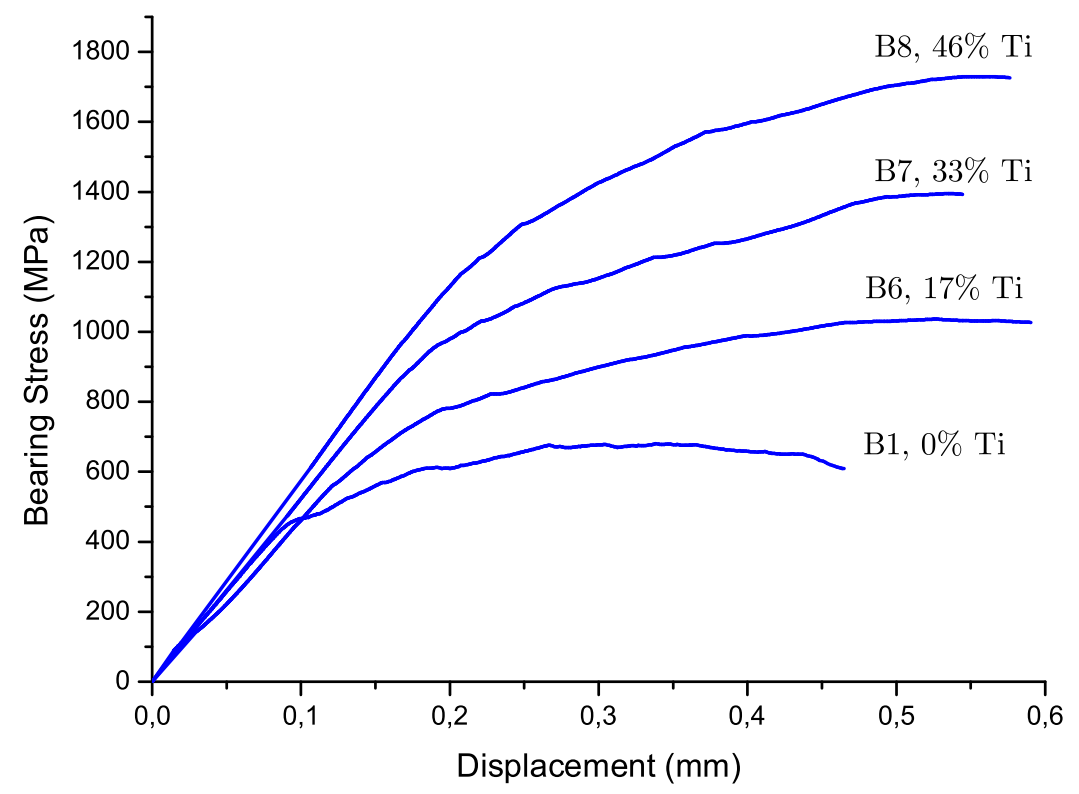

Fig. 3. Relation between the bearing stress and the cross-head displacement. 


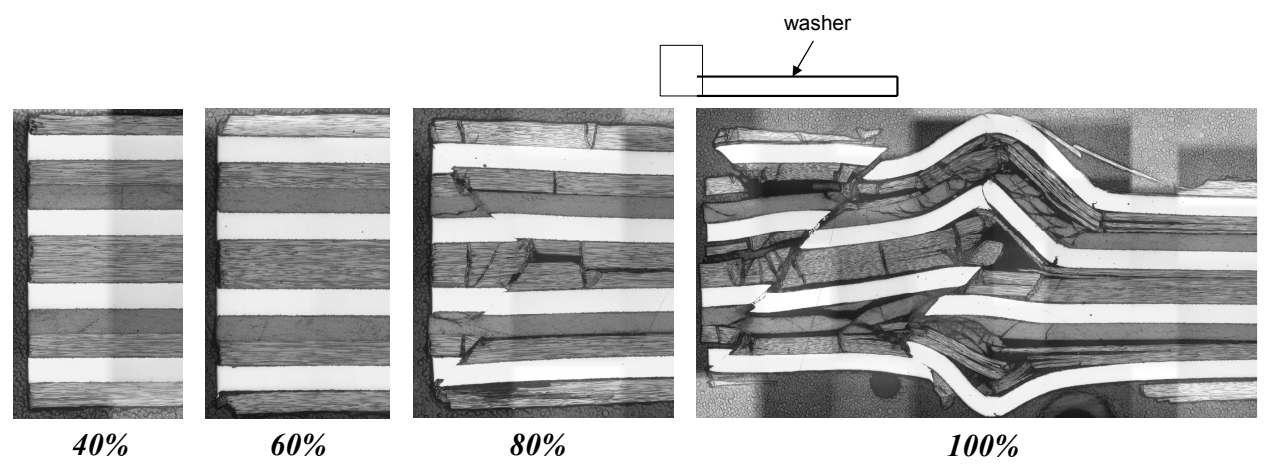

Specimen B7/TT2

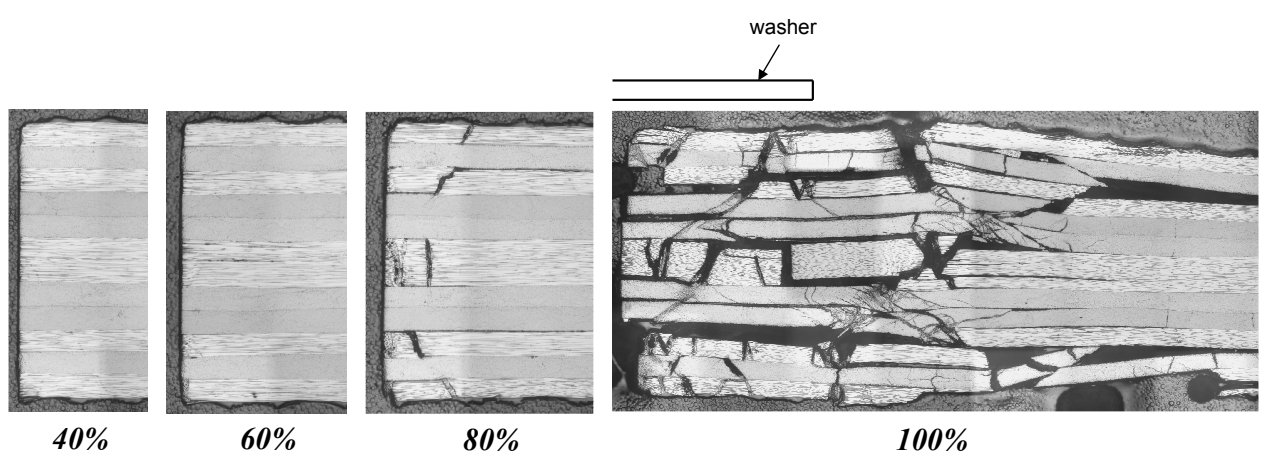

Fig. 4. Optical micrographies of the B1 and B7/TT2 test specimens. 


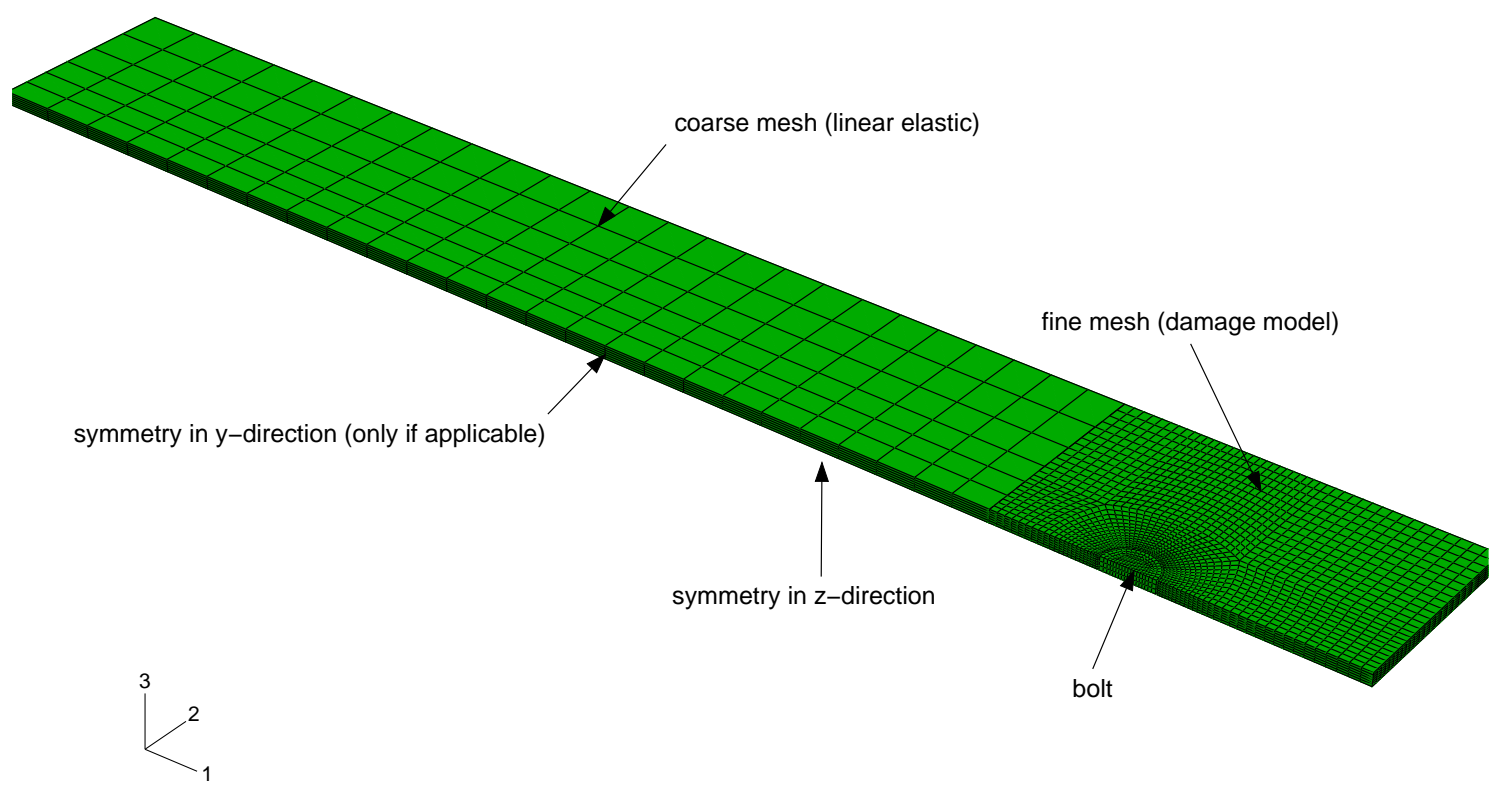

Fig. 5. FE mesh of the bearing specimens. 
$40 \%$ of failure stress

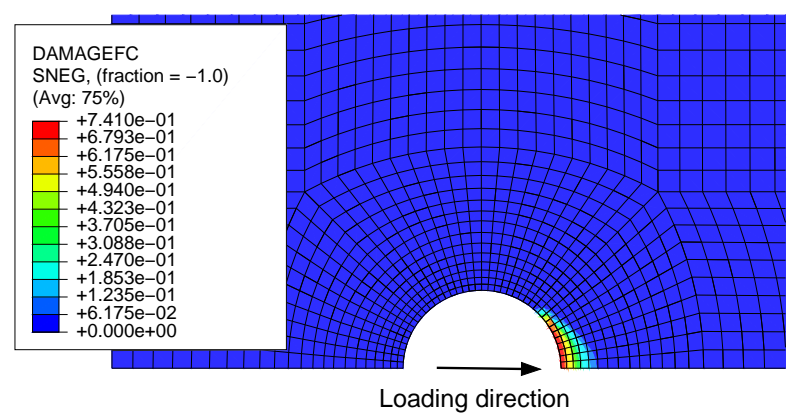

L.

$80 \%$ of failure stress

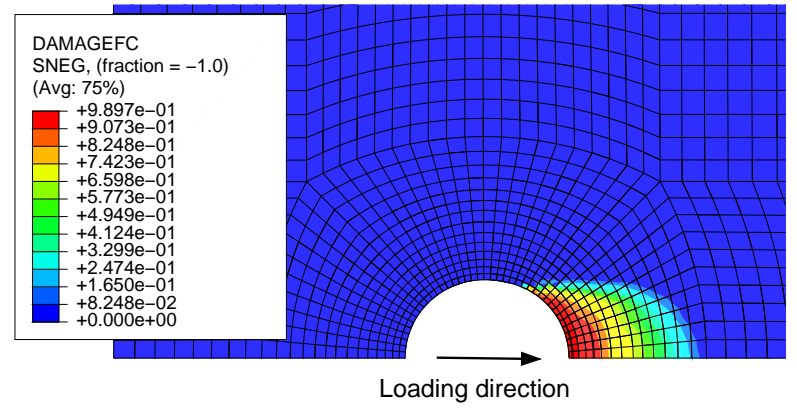

$L_{x}$
$60 \%$ of failure stress

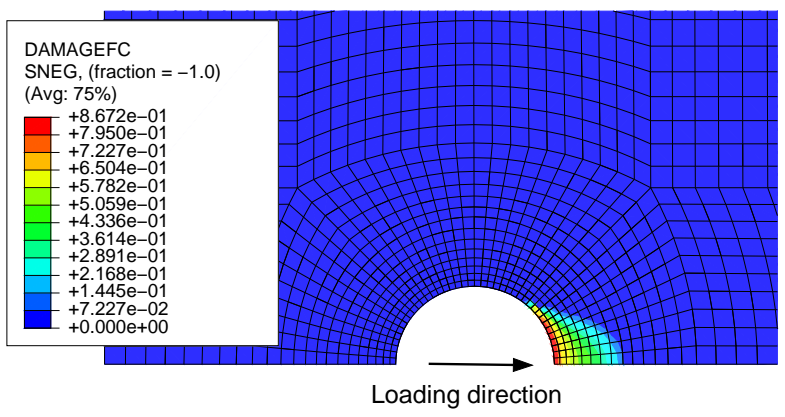

$\stackrel{1}{L}$

$100 \%$ of failure stress

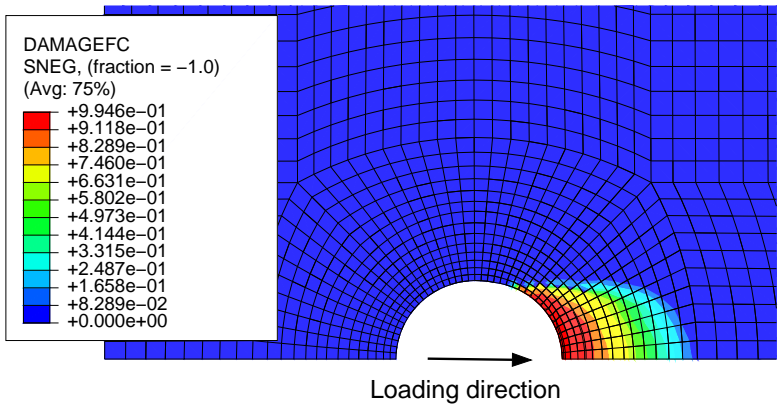

$L_{x}$

Fig. 6. Predicted evolution of fibre kinking in top $0^{\circ}$ ply of the B7/TT2 specimen. 
$40 \%$ of failure stress

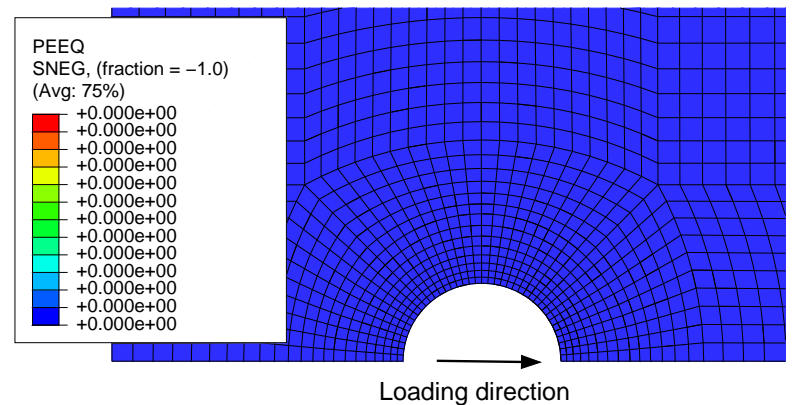

$\check{L}_{x}$

$80 \%$ of failure stress

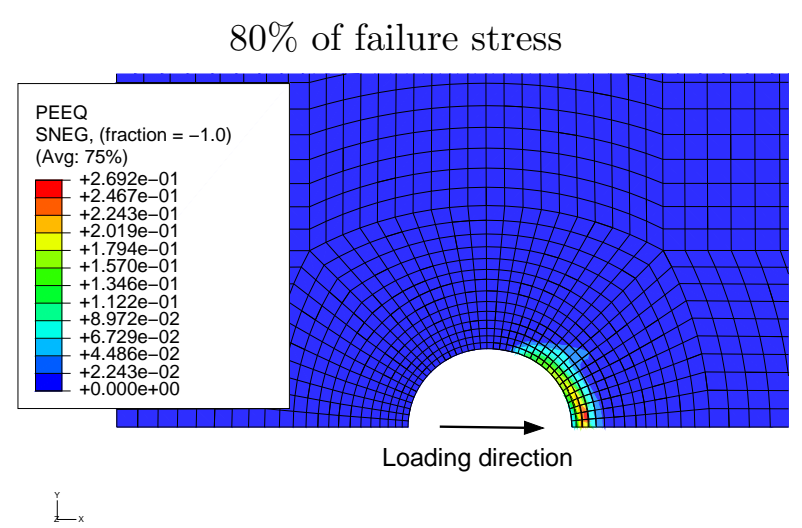

Ĺx
$60 \%$ of failure stress

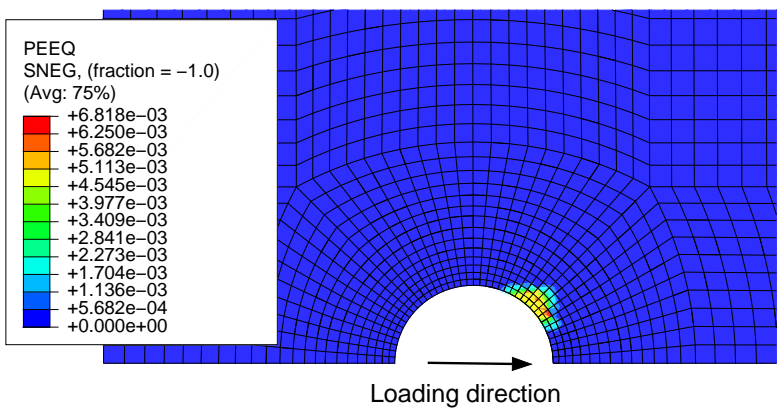

Lx

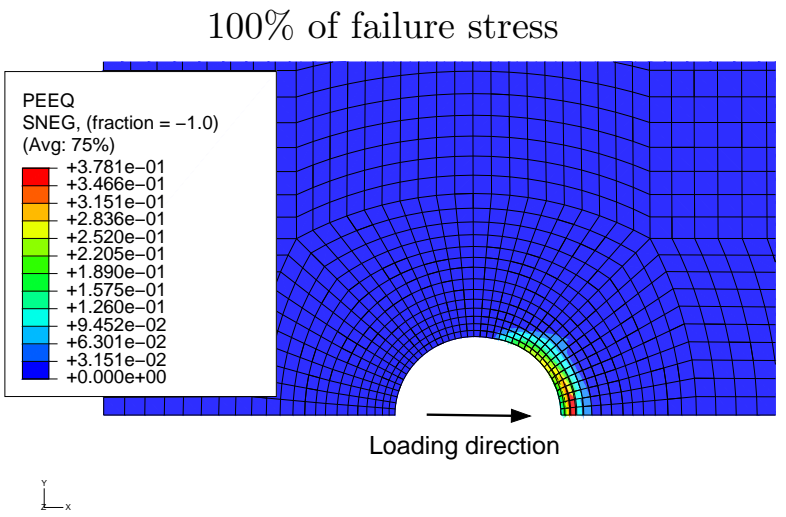

Fig. 7. Predicted evolution of plastic deformation in the top titanium ply of the B7/TT2 specimen. 


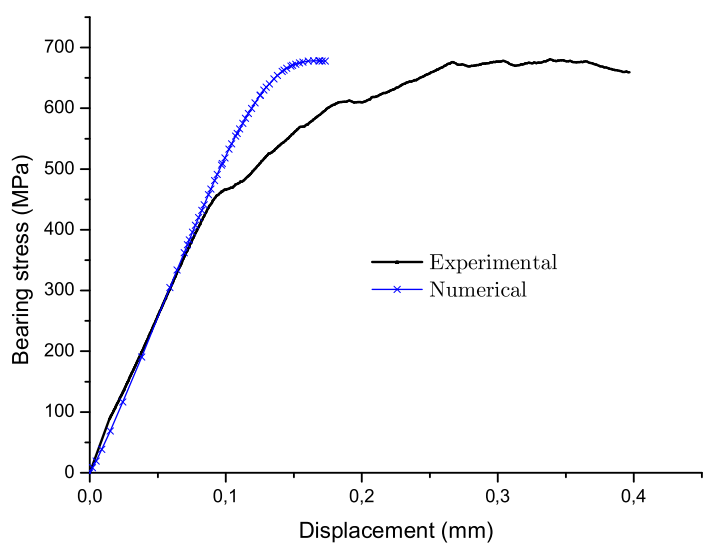

a) B1

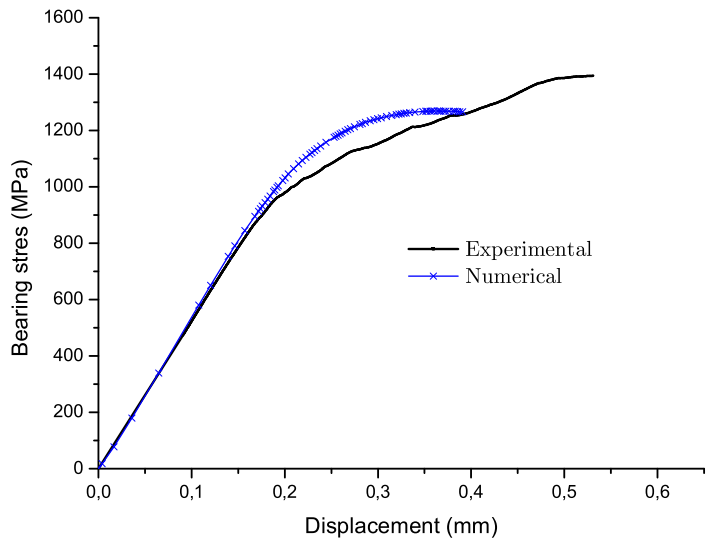

c) $\mathrm{B} 7 / \mathrm{TT} 7$

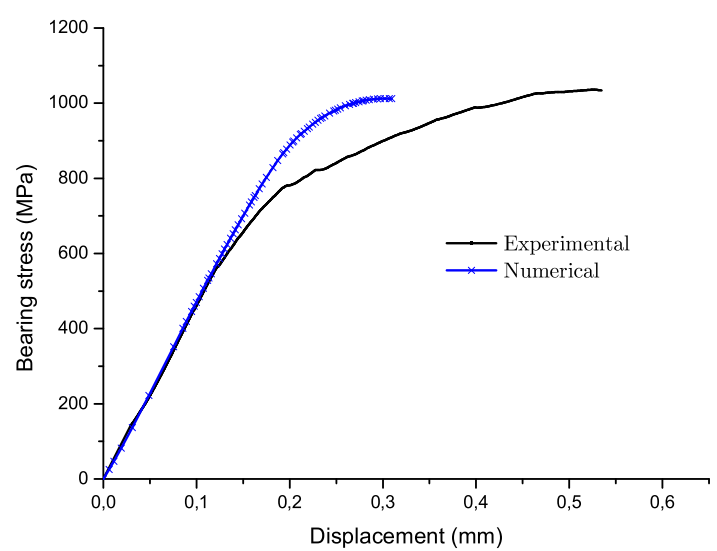

b) B6/TT1

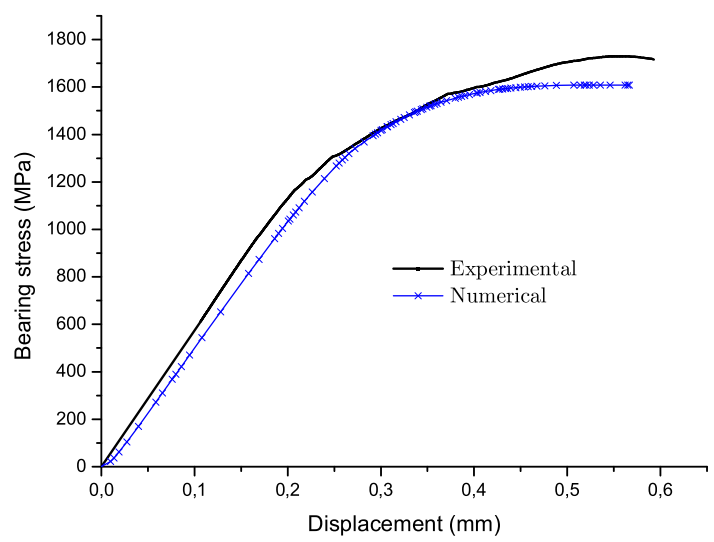

d) $\mathrm{B} 8 / \mathrm{TT} 4$

Fig. 8. Predicted and experimental bearing stress-bolt displacement relations. 


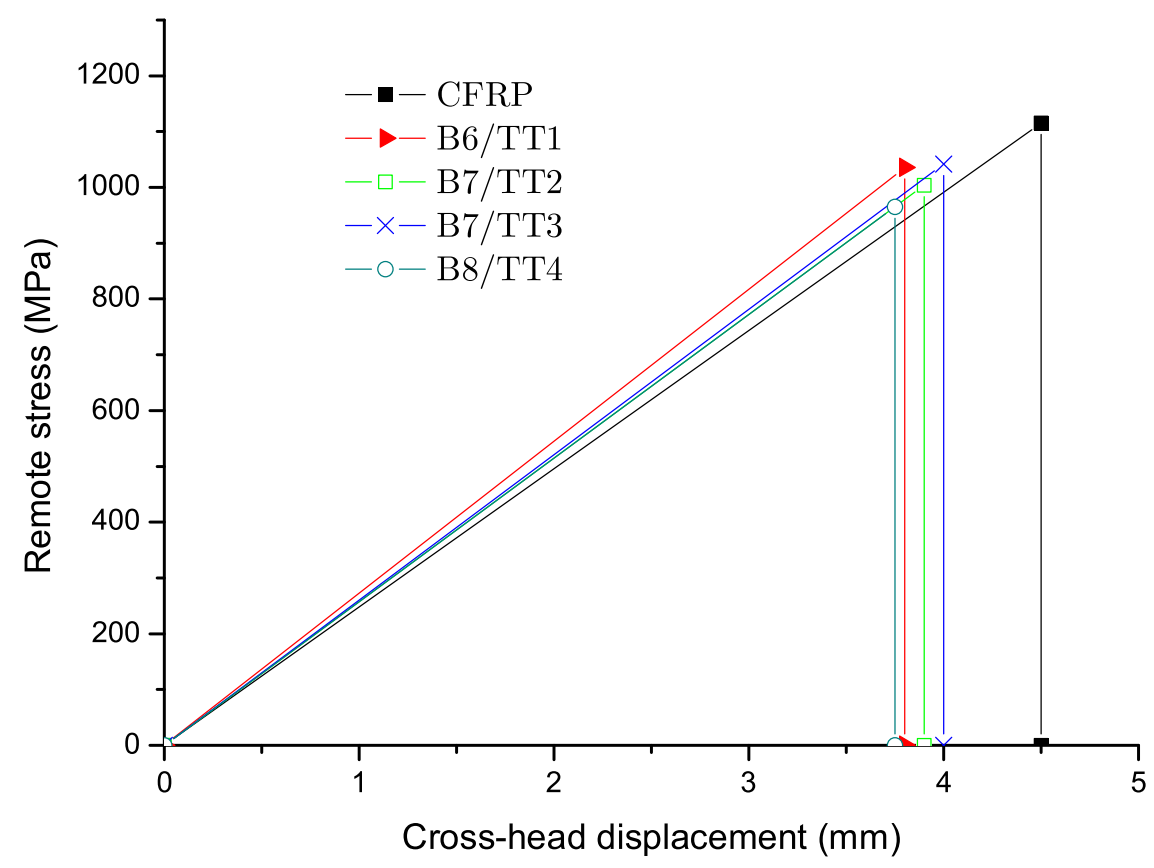

Fig. 9. Relation between the remote stress and the displacement for the transition specimens. 


\section{B8/TT4}

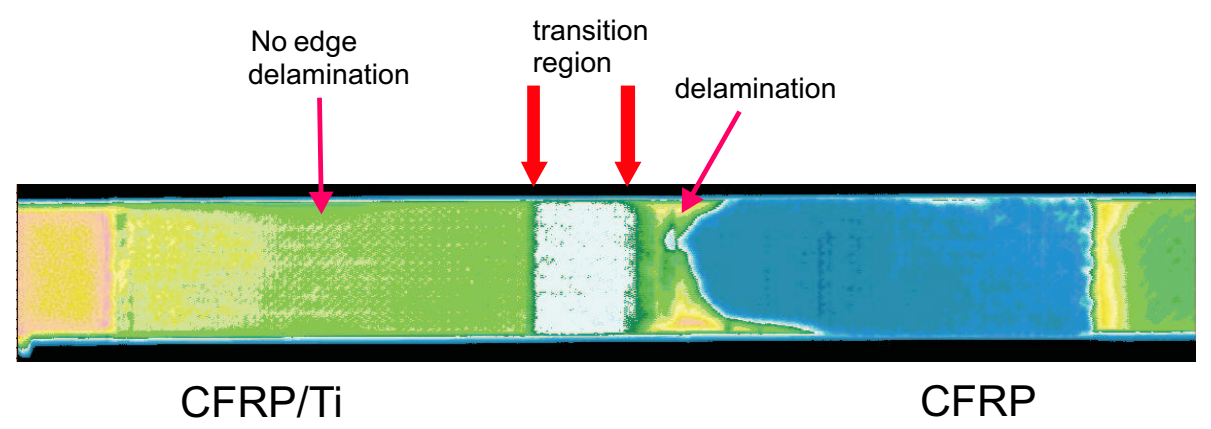

Fig. 10. C-Scan of the specimen B8/TT4. 


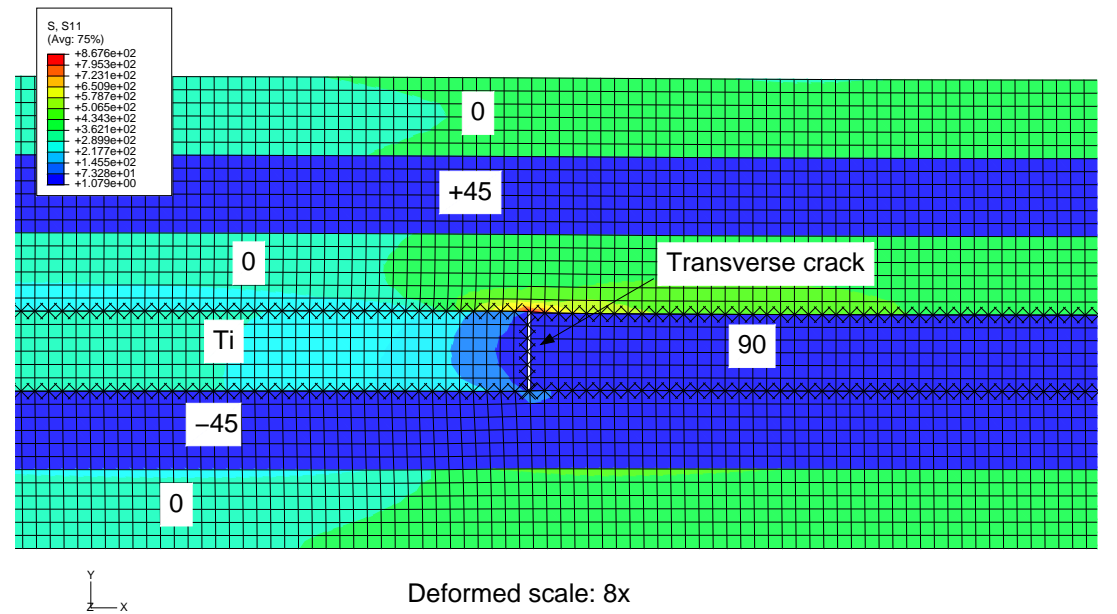

Fig. 11. Detail of B6/TT1 test specimen at $\sigma^{\infty}=225 \mathrm{MPa}$. 


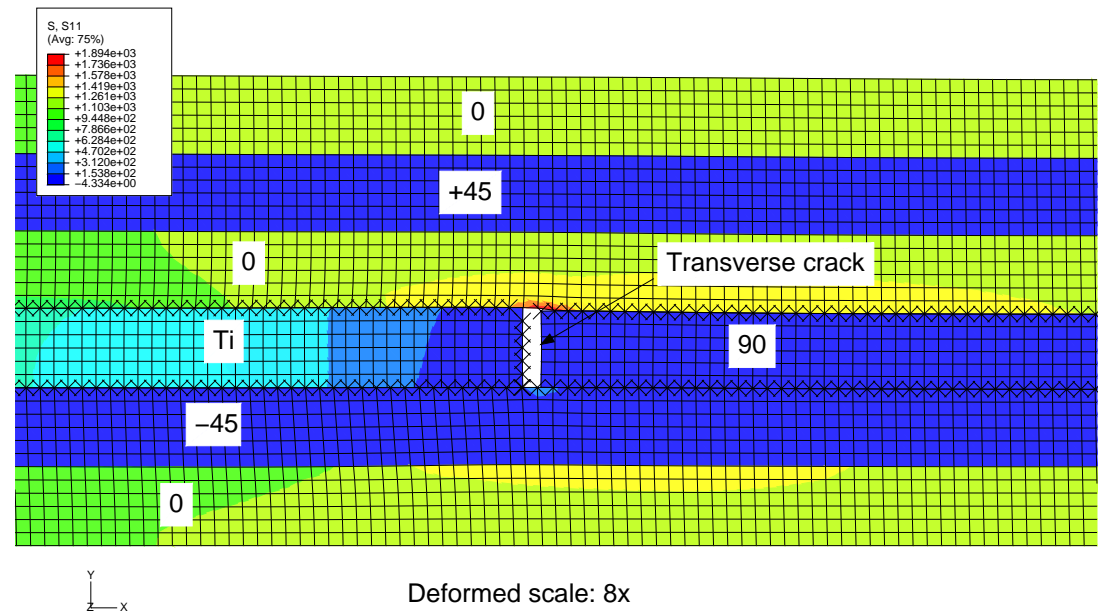

Fig. 12. Detail of B6/TT1 test specimen at $\sigma^{\infty}=651 \mathrm{MPa}$. 


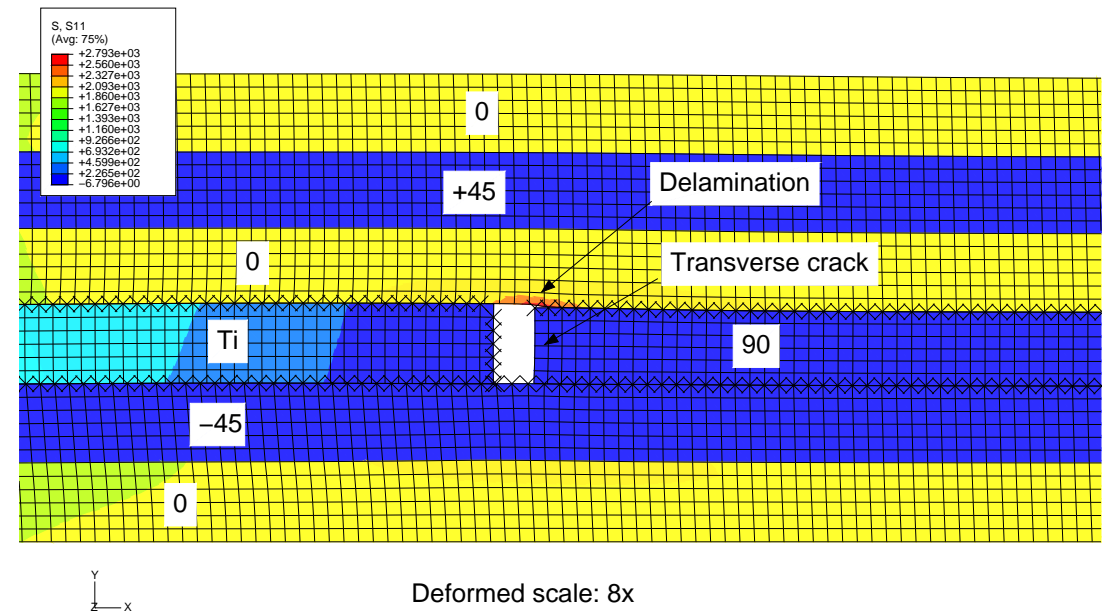

Fig. 13. Predicted critical region of the B6/TT1 test specimen. 

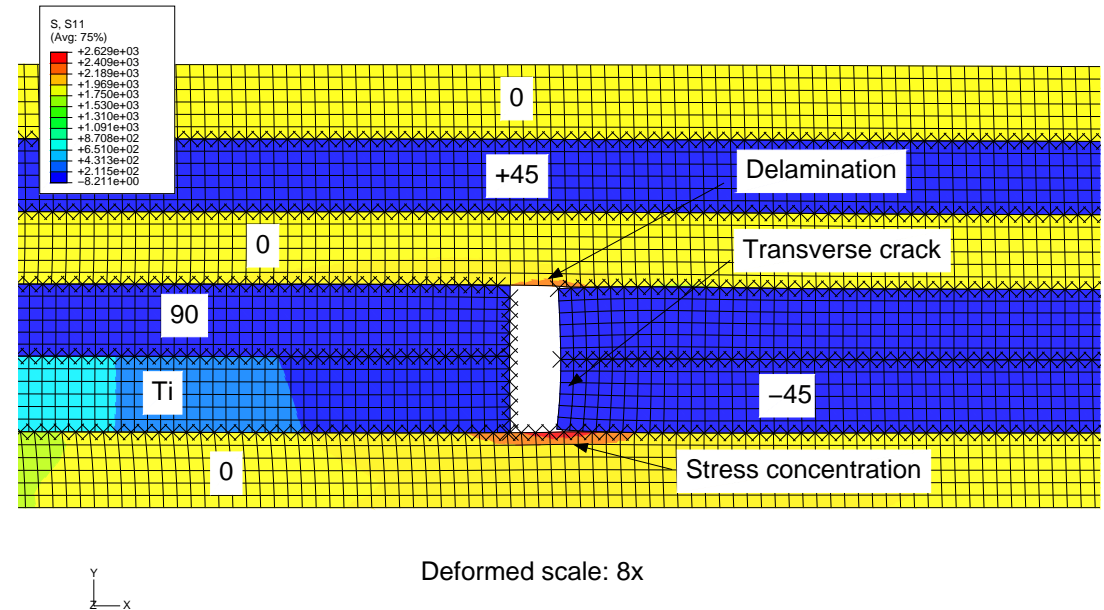

Deformed scale: $8 x$

Fig. 14. Predicted critical region of the B7/TT2 test specimen. 


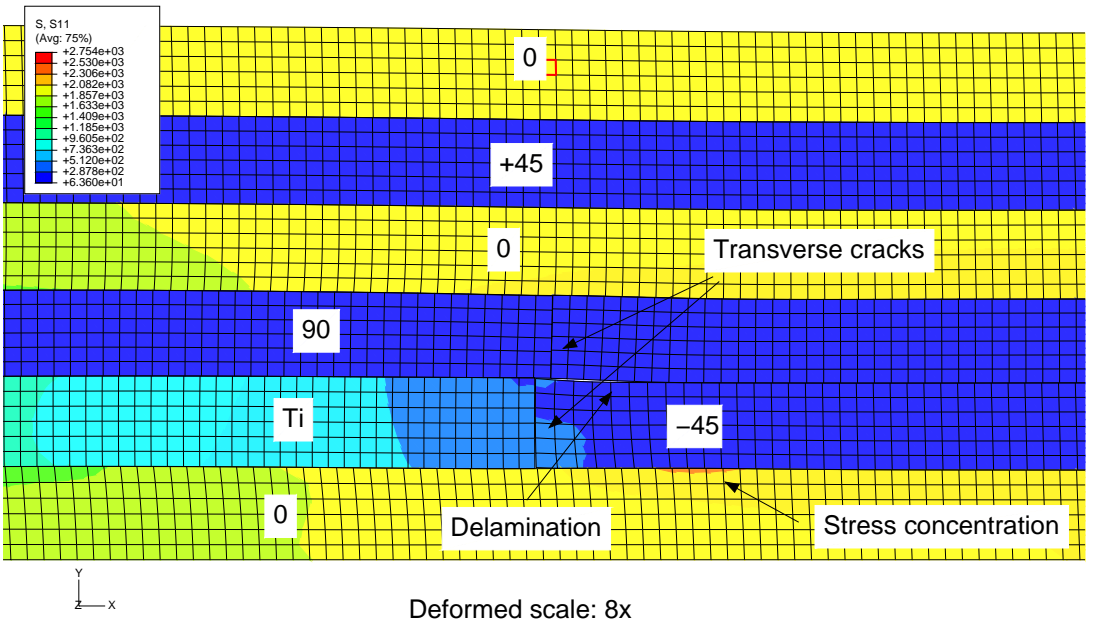

Fig. 15. Predicted critical region of the B7/TT3 test specimen. 


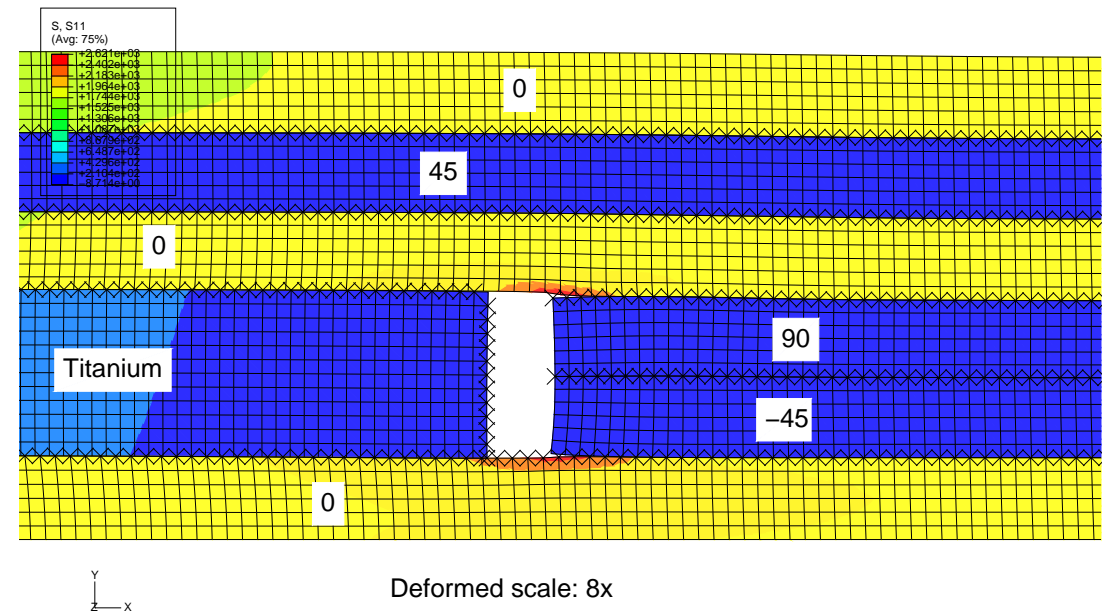

Fig. 16. Predicted critical region of the B8/TT4 test specimen. 


\section{List of Tables}

$1 \quad$ Elastic properties of M40-J/CYCOM 977-2 carbon epoxy. 32

$2 \quad$ Ply strengths of M40-J/CYCOM 977-2 carbon epoxy. 33

$3 \quad$ Interlaminar fracture toughness. $\quad 34$

$4 \quad$ In-situ strengths for M40-J/CYCOM 977-2 carbon epoxy. 35

$5 \quad$ Mechanical properties of the titanium plies. 36

$6 \quad$ Stacking sequence of the test specimens. $\quad 37$

7 Details of the bearing test specimens. 38

$8 \quad$ Configuration for ply-substitution transition specimens. 39

$9 \quad$ Bearing strengths. $\quad 40$

10 Bearing stresses at the onset of non-linearity. $\quad 41$

11 Test-analysis correlation for the transition specimens. 42

12 Remote failure stress for the bearing and transition specimens. 43 
Table 1

Elastic properties of M40-J/CYCOM 977-2 carbon epoxy.

\begin{tabular}{cccccc}
\hline \hline $\mathrm{E}_{1}(\mathrm{MPa})$ & $\mathrm{E}_{2}(\mathrm{MPa})$ & $\mathrm{G}_{12}(\mathrm{MPa})$ & $\mathrm{G}_{23}(\mathrm{MPa})$ & $v_{12}$ & $v_{23}$ \\
\hline 211424 & 6287 & 3895 & 2095.7 & 0.30 & 0.5 \\
\hline \hline
\end{tabular}


Table 2

Ply strengths of M40-J/CYCOM 977-2 carbon epoxy.

\begin{tabular}{ccccc}
\hline \hline $\mathrm{X}_{T}(\mathrm{MPa})$ & $\mathrm{X}_{C}(\mathrm{MPa})$ & $\mathrm{Y}_{T}(\mathrm{MPa})$ & $\mathrm{Y}_{C}(\mathrm{MPa})$ & $S_{L}(\mathrm{MPa})$ \\
\hline 2132 & 994 & 47 & 217 & 67 \\
\hline \hline
\end{tabular}


Table 3

Interlaminar fracture toughness.

\begin{tabular}{ccc}
\hline \hline & Titanium-CFRP & CFRP-CFRP \\
\hline$G_{I c}(\mathrm{~N} / \mathrm{mm})$ & 0.179 & 0.199 \\
$G_{I I c}(\mathrm{~N} / \mathrm{mm})$ & 2.784 & 0.699 \\
\hline \hline
\end{tabular}


Table 4

In-situ strengths for M40-J/CYCOM 977-2 carbon epoxy.

\begin{tabular}{ccc}
\hline \hline Ply & $\mathrm{Y}_{T}^{\text {is }}(\mathrm{MPa})$ & $\mathrm{S}_{L}^{\text {is }}(\mathrm{MPa})$ \\
\hline Outer ply, $\mathrm{t}=0.25 \mathrm{~mm}$ & 50.5 & 80.6 \\
Inner ply, $\mathrm{t}=0.25 \mathrm{~mm}$ & 79.8 & 100.4 \\
\hline \hline
\end{tabular}


Table 5

Mechanical properties of the titanium plies.

\begin{tabular}{rcc}
\hline \hline $\mathrm{E}(\mathrm{GPa})$ & $\sigma_{0.2 \%}(\mathrm{MPa})$ & $\sigma_{r}(\mathrm{MPa})$ \\
\hline 116 & 1534 & 1634 \\
\hline \hline
\end{tabular}


Table 6

Stacking sequence of the test specimens.

\begin{tabular}{cc}
\hline \hline Reference & Lay-up \\
\hline B1/TT0 & {$[0 /+45 / 0 / 90 /-45 / 0]_{s}$} \\
B6/TT1 & {$[0 /+45 / 0 / \mathrm{Ti} 90 /-45 / 0]_{s}$} \\
B7/TT2 & {$[0 / \mathrm{Ti}+45 / 0 / 90 / \mathrm{Ti}-45 / 0]_{s}$} \\
B7/TT3 & {$[0 / \mathrm{Ti}+45 / 0 / 90 / \mathrm{Ti}-45 / 0]_{s}$} \\
B8/TT4 & {$[0 / \mathrm{Ti}+45 / 0 / \mathrm{Ti} 90 / \mathrm{Ti}-45 / 0]_{s}$} \\
\hline \hline
\end{tabular}


Table 7

Details of the bearing test specimens.

\begin{tabular}{ccc}
\hline \hline Ref. & Geometry & Observations \\
\hline B1/TT0 & $w / d=7, e / d=4$ & Reference \\
B6/TT1 & $w / d=7, e / d=4$ & Hybrid \\
B7/TT2 & $w / d=7, e / d=4$ & Hybrid \\
B8/TT4 & $w / d=7, e / d=4$ & Hybrid \\
\hline \hline
\end{tabular}

$e$-end distance; $d$-hole diameter; $\quad w$-width 
Table 8

Configuration for ply-substitution transition specimens.

\begin{tabular}{ccc}
\hline \hline Reference & Step distance & Dimensions $(l \times t \times w)(\mathrm{mm})$ \\
\hline B6/TT1 & $15 \mathrm{~mm}$ & $110 \times 3 \times 15$ \\
B7/TT2 & $15 \mathrm{~mm}$ & $110 \times 3 \times 15$ \\
$\mathrm{~B} 7 / \mathrm{TT} 3$ & $5 \mathrm{~mm}$ & $110 \times 3 \times 15$ \\
$\mathrm{~B} 8 / \mathrm{TT} 4$ & $15 \mathrm{~mm}$ & $110 \times 3.25 \times 15$ \\
\hline \hline
\end{tabular}

l-length; t-thickness; $\quad$ w-width 
Table 9

Bearing strengths.

\begin{tabular}{cccc}
\hline \hline Ref. & $\bar{\sigma}^{b}$ (MPa)-FE & $\bar{\sigma}^{b}(\mathrm{MPa})$-Exp. & Error $(\%)$ \\
\hline B1 & 678.3 & 680.6 & 0.3 \\
B6/TT1 & 1036.2 & 1012.4 & -2.3 \\
B7/TT2 & 1269.1 & 1395.5 & -9.1 \\
B8/TT3 & 1608.7 & 1729.1 & -7.0 \\
\hline \hline
\end{tabular}


Table 10

Bearing stresses at the onset of non-linearity.

\begin{tabular}{cccc}
\hline \hline Ref. & $\sigma_{e}^{b}(\mathrm{MPa})-\mathrm{FE}$ & $\sigma_{e}^{b}(\mathrm{MPa})$-Exp. & Error (\%) \\
\hline B1 & 500 & 441.7 & +13.2 \\
$\mathrm{~B} 6 / \mathrm{TT} 1$ & 650 & 550.1 & +18.2 \\
$\mathrm{~B}$ /TT2 & 767 & 758.5 & +1.1 \\
$\mathrm{~B} 8 / \mathrm{TT} 3$ & 1000 & 933.5 & +7.1 \\
\hline \hline
\end{tabular}


Table 11

Test-analysis correlation for the transition specimens.

\begin{tabular}{cccc}
\hline \hline Ref. & $\bar{\sigma}^{\infty}(\mathrm{MPa}), \mathrm{FE}$ & $\bar{\sigma}^{\infty}(\mathrm{MPa})$, test & Error $(\%)$ \\
\hline B6/TT1 & ref. & 1069.2 & $\mathrm{n} / \mathrm{a}$ \\
$\mathrm{B} 7 / \mathrm{TT} 2$ & 1007.4 & 1005.9 & +0.1 \\
$\mathrm{~B} 7 / \mathrm{TT} 3$ & 1087.2 & 1024.4 & +6.1 \\
$\mathrm{~B} 8 / \mathrm{TT} 4$ & 996.5 & 988.7 & +0.8 \\
\hline \hline
\end{tabular}


Table 12

Remote failure stress for the bearing and transition specimens.

\begin{tabular}{ccc}
\hline \hline Ref. & $\bar{\sigma}^{\infty}(\mathrm{MPa})$, transition & $\bar{\sigma}^{\infty}(\mathrm{MPa})$, bearing \\
\hline B1/TT0 & 1091 & 36 \\
B6/TT1 & 1069 & 142 \\
B7/TT2 & 1006 & 195 \\
B7/TT3 & 1024 & 195 \\
B8/TT4 & 989 & 242 \\
\hline \hline
\end{tabular}

